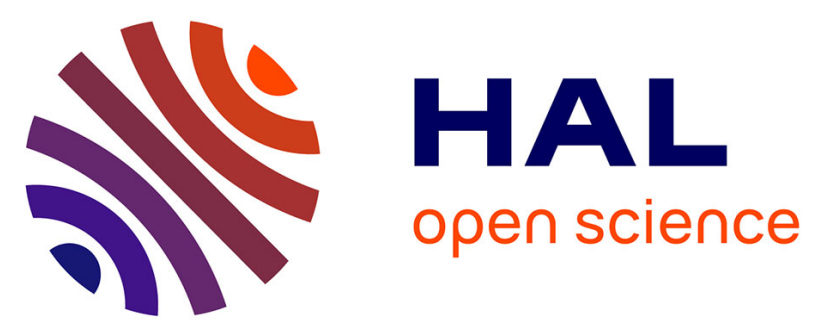

\title{
Performance of Metarhizium anisopliae-treated foam in combination with Phytoseiulus longipes Evans against Tetranychus evansi Baker \& Pritchard (Acari: Tetranychidae)
}

Ginette y Azandémè Hounmalon, Nguya K Maniania, Saliou Niassy, Simon

Fellous, Serge Kreiter, Emilie Delétré, Komi Km Fiaboe, Thibaud Martin

\section{To cite this version:}

Ginette y Azandémè Hounmalon, Nguya K Maniania, Saliou Niassy, Simon Fellous, Serge Kreiter, et al.. Performance of Metarhizium anisopliae-treated foam in combination with Phytoseiulus longipes Evans against Tetranychus evansi Baker \& Pritchard (Acari: Tetranychidae). Pest Management Science, 2018, 74 (12), pp.2835-2841. 10.1002/ps.5073 . hal-02621300

\section{HAL Id: hal-02621300 \\ https://hal.inrae.fr/hal-02621300}

Submitted on 26 May 2020

HAL is a multi-disciplinary open access archive for the deposit and dissemination of scientific research documents, whether they are published or not. The documents may come from teaching and research institutions in France or abroad, or from public or private research centers.
L'archive ouverte pluridisciplinaire HAL, est destinée au dépôt et à la diffusion de documents scientifiques de niveau recherche, publiés ou non, émanant des établissements d'enseignement et de recherche français ou étrangers, des laboratoires publics ou privés. 


\title{
Performance of Metarhizium anisopliae-treated foam in combination with Phytoseiulus longipes Evans against Tetranychus evansi Baker \& Pritchard (Acari: Tetranychidae) $\dagger$
}

\author{
Ginette Y Azandémè Hounmalon, ${ }^{\mathrm{a}, \mathrm{b}^{*}}$ Nguya K Maniania, ${ }^{\mathrm{b}}$ Saliou Niassy,

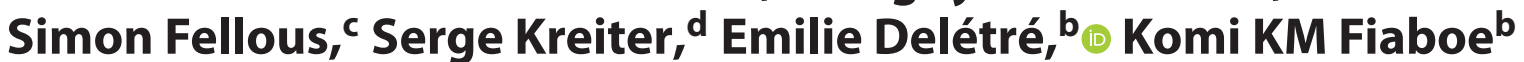 \\ and Thibaud Martin ${ }^{a, b}$
}

\begin{abstract}
BACKGROUND: Tetranychus evansi (Te) is an exotic pest of solanaceous crops in Africa. The predatory mite Phytoseiulus longipes $(P I)$ and the fungus Metarhizium anisopliae $(\mathrm{Ma})$ are potential biocontrol agents of Te. The present study investigated the efficacy of fungus-treated foam placed above or below the third Te-infested tomato leaf. The persistence of fungus-treated foam and the performance of $P I$ with and without fungus-treated foam were evaluated.

RESULTS: The fungus-treated foam was effective when Te infestation was below the third tomato leaf as no damage was recorded on any of the upper tomato leaves up to $\mathbf{3 0}$ days post-treatment. However, in the control treatments, the infestation increased considerably from $9 \pm 0.3 \%$ to $100 \pm 0 \%$ (mean \pm standard error) at 15 days post-treatment. The reuse of the fungus-treated foam at 15, 30 and 45 days post-treatment resulted in $19 \pm 1.4 \%, 25 \pm 1.2 \%$ and $54 \pm 2.1 \%$, respectively, infestation by Te. The fungus-treated foam and PI alone were efficient, but there was no benefit to combining them for use against Te.
\end{abstract}

CONCLUSION: The fungus-treated foam is an effective method to optimise the use of $M a$ in screenhouse conditions. These two control agents could be integrated in an integrated pest management strategy for crop protection. However, these results need to be confirmed in large field trials.

(C) 2018 Society of Chemical Industry

Keywords: fungus-treated foam; red spider mites; emulsifiable formulation; tomato plant; predatory mites

\section{INTRODUCTION}

The tomato spider mite (TSM) is among the key pests affecting tomato production in sub-Saharan Africa. ${ }^{1-5}$ Yield losses of between 65 and 90\% have been reported in small-holder production in East and West Africa. ${ }^{6,7}$ TSM is an invasive species that originated from South America ${ }^{8,9}$ and its management is mainly based on frequent applications of synthetic chemical acaricides. Up to 12 applications per month have been reported on tomato crops. ${ }^{7-10}$ However, use of these chemicals is problematic as they are ineffective and costly, ${ }^{6-8}$ and mites have developed resistance to various classes of these chemical acaricides. ${ }^{11,12}$ They are also harmful to the environment and residues lead to food contamination. This has prompted the search for environmentally friendly alternatives such as biological control using predators and/or entomopathogenic fungi. ${ }^{13}$

Entomopathogenic fungi have been reported to be virulent against Tetranychus evansi and Tetranychus urticae Koch (Acari: Tetranychidae) in the screenhouse and in the field. ${ }^{14,15}$ An isolate of Metarhizium anisopliae (Sorok.) Vuill. is commercially available under the trade name of Achieve ${ }^{\circledR}$ from Real IPM (Nairobi, Kenya) for the control of TSM. Use of entomopathogenic fungi for the inundative biological control of spider mites faces challenges, including high cost as a consequence of the large amount of inoculum used in spraying and the frequent applications necessitated by the short persistence of the inoculum in the crop and vulnerability to ultraviolet (UV) photodegradation. ${ }^{16}$ As an alternative, a Brazilian predatory mite Phytoseiulus longipes Evans has been found in

\footnotetext{
* Correspondence to: GY Azandémè Hounmalon, National University of Agriculture (UNA), School of Horticulture and Green Space Management (EHAEV), BP 43 Kéou. E-mail: fidelerocher@gmail.com Current address: International Institute for Tropical Agriculture (IITA), 08 BP 0932. Cotonou - Bénin

$\dagger$ The work was carried out at the International Centre of Insect Physiology and Ecology (ICIPE), Department of African Insect Science for Food and Health, PO Box 30772-00100, Nairobi, Kenya.

a Cirad, UPR Hortsys, Université de Montpellier, Montpellier, France

b Plant Health Department, ICIPE, Nairobi, Kenya

c INRA, UMR CBGP, Montferrier-sur-Lez, France

d Montpellier SupAgro, UMR CBGP, Montferrier-sur-Lez, France
} 
association with T. evansi ${ }^{17}$ and has been reported to be effective against T. evansi in the laboratory and greenhouse. ${ }^{17-19}$ These two biological control agents could therefore be integrated as components of a tomato spider mite management strategy. Furthermore, young females of T. evansi during the day shows gregarious behaviour and spreads on the tomato plant when its resources become limited ${ }^{20}$. This behaviour could therefore be exploited to develop a control strategy based on fungus-impregnated devices placed along the stalk for dissemination of conidia among migrant females which can in turn contaminate other stages on the leaves. This strategy would allow for longer persistence of the inoculum and save on cost. As M. anisopliae has been shown not to be pathogenic to $P$. longipes, the two control agents could be combined for greater efficacy.

The present study evaluated (i) the performance of the fungus-treated foam according to the location of mites on the tomato leaf plant; (ii) the persistence of the fungus-treated foam, and (iii) the the effect on red spider mite infestations of tomato plants of applications of both fungus-treated foam and the release of the predatory mite $P$. longipes.

\section{MATERIALS AND METHODS}

\subsection{Plants}

Seeds of Solanum lycopersicum L. var. 'Money Maker' from the East African Seed Company (Nairobi, Kenya) were sown in soil enriched with compost in plastic seed trays. Plants ( 21 days old) were transplanted into plastic pots $20.5 \mathrm{~cm}$ in diameter and $20 \mathrm{~cm}$ in height, each containing a mixture of red soil plus bovine manure (3:1), and placed in a greenhouse until they were 45 days old and had at least four completely developed leaves. The plants were watered daily and each pot was top dressed with $3 \mathrm{~g}$ of calcium ammonium nitrate [CAN $(26 \% \mathrm{~N})$ from Jumbo Agrovet, Nairobi, Kenya] 2 weeks after transplanting. These were then used for the rearing of spider mites and for experiments. Subsequently, 45-day-old plants with at least five completely developed leaves were used in the experiments, with the unfolded primary leaves being used either for the experiments or for the rearing of spider mites.

\subsection{Mites}

The red spider mites, T. evansi, used in this study were obtained from a regularly regenerated colony maintained at the International Centre of Insect Physiology and Ecology (ICIPE) on potted tomato plants of the variety 'Money Maker'. They were maintained at a temperature of $25 \pm 1{ }^{\circ} \mathrm{C}$ at $50-70 \%$ relative humidity $(\mathrm{RH})$ and with a 12- $\mathrm{h}$ photoperiod. Quiescent deutonymphs were collected from the mite culture using a fine camel hair brush and placed on tomato leaf discs. Two days later, newly emerged adult female mites were selected and used in the experiments.

\subsection{Predatory mites}

Phytoseiulus longipes was imported into Kenya in September 2005 from a Brazilian colony and maintained at ICIPE at $25 \pm 1{ }^{\circ} \mathrm{C}$ and $60 \pm 10 \% \mathrm{RH}$ and with a photoperiod of $12: 12 \mathrm{~h}$ light:dark. Phytoseiulus longipes had access to all developmental stages of T. evansi on infested tomato plants.

\subsection{Fungus}

The M. anisopliae isolate ICIPE 78 used in this experiment was obtained from the ICIPE Arthropod Germplasm Centre. It was

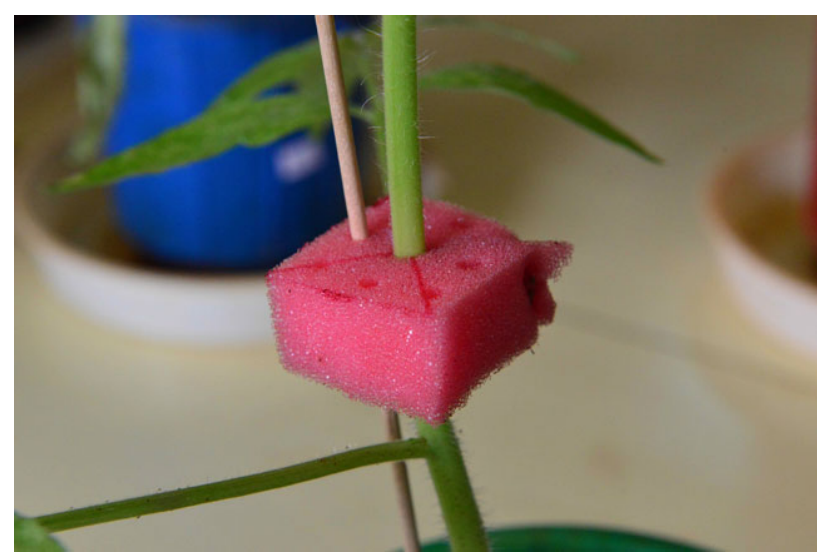

Figure 1. Bioassay setup.

selected for its virulence against T. evansi $i^{14-22}$ and is commercially available as Achieve (Metarhizium78). Conidia were formulated in an emulsifiable formulation (Tween 80, corn oil, and sterile distilled water in a ratio of $0.25: 6: 93.75)$. A concentration of $1 \times 10^{8}$ conidia $\mathrm{mL}^{-1}$ was used in all the experiments according to Bugueme et al. ${ }^{15}$ Conidia were harvested by scraping the surface of 3-week-old sporulating cultures grown on Sabouraud dextrose agar (SDA) in Petri dishes at $26 \pm 2{ }^{\circ} \mathrm{C}$. Conidia were suspended in $20 \mathrm{~mL}$ of sterile distilled water containing $0.05 \%$ Triton X-100. The suspension was vortexed for $5 \mathrm{~min}$ to produce a homogenous conidial suspension. The viability of conidia was then determined by spread-plating $0.1 \mathrm{~mL}$ of the suspension (titrated to $3.0 \times 10^{6}$ conidia $\mathrm{mL}^{-1}$ ) on SDA plates. A sterile microscope cover slip was placed on each plate. Plates were incubated at $26 \pm 2{ }^{\circ} \mathrm{C}$ and the percentage germination was determined for 100 spores in each plate after $24 \mathrm{~h}$ using a compound microscope at $400 \times$ magnification. Conidial germination was $90 \pm 0.5 \%$.

\subsection{Bioassays}

\subsubsection{Inoculation of foams and treatments}

The foam ( $2 \mathrm{~cm}$ in diameter and $2 \mathrm{~cm}$ thick) used in this experiment was purchased from a local supermarket in Nairobi. A hole $5 \mathrm{~mm}$ in diameter was created in the middle in order to fit the foam around the stem of the tomato plant (Fig. 1). The foam was impregnated with $2 \mathrm{~mL}$ of emulsifiable formulation of the fungal conidia as described above and then affixed to the stem. In the control treatments, foam was impregnated with emulsifiable formulation without fungal conidia. The foam was fixed around the tomato stem in such a way that leaves L1 and L2 were below the foam and leaves L3, L4 and L5 above the foam (Fig. 2, experiment 1). The tomato plants were artificially infested with $100 \mathrm{~T}$. evansi females on L2 or L3. The following treatments were applied: T1, untreated control with $T$. evansi infestation on leaf $L 2$ below the foam; T2, untreated control with T. evansi infestation on leaf $L 3$ above the foam; T3: fungus-treated foam with T. evansi infestation on leaf L2 below the foam; and T4, fungus-treated foam with $T$. evansi infestation on leaf $L 3$ above the foam (Fig. 2, experiment 1). Treatments were replicated four times.

\subsubsection{Interaction between M. anisopliae-treated foam and the predatory mite $\mathrm{P}$. longipes on $\mathrm{T}$. evansi}

Another experiment was carried out whereby predatory mites were included, with the following treatments being applied (Fig. 2, experiment 2): T5, untreated foam with $T$. evansi and $P$. longipes 


\section{Experiment 1}

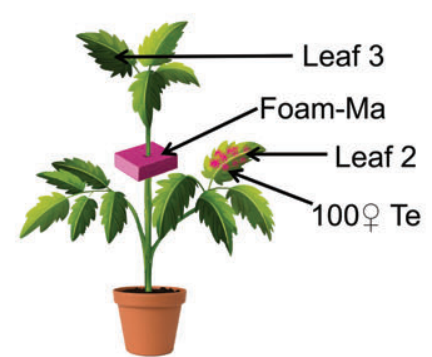

T1: Untreated control

( $T e$ infestation on leaf $L 2$ below the foam)

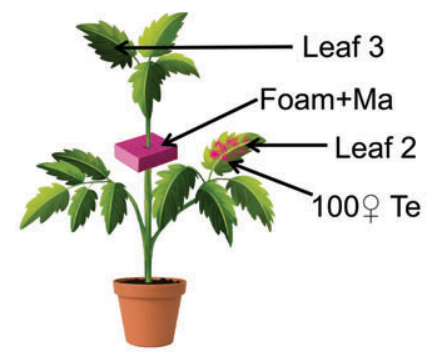

T3: Fungus-treated foam

( $T e$ infestation on leaf L2 below the foam)

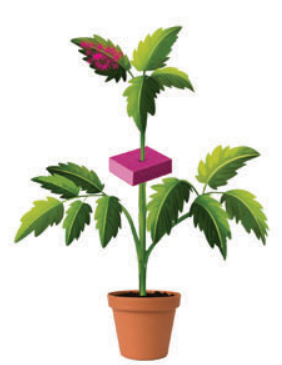

T2: Untreated control

(Te infestation on leaf L3 above the foam)

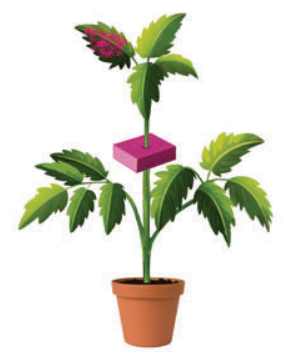

T4: Fungus-treated foam

(Te infestation on leaf L3 above the foam)

\section{Experiment 2}

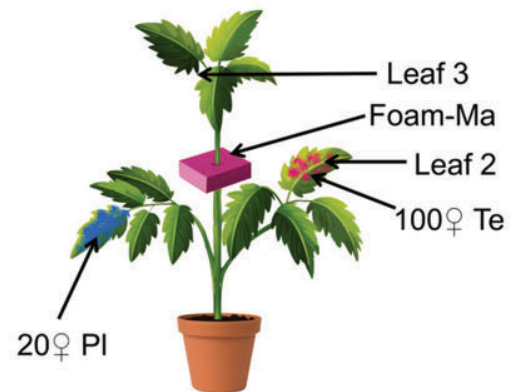

Untreated foam T5 (Te + PI)

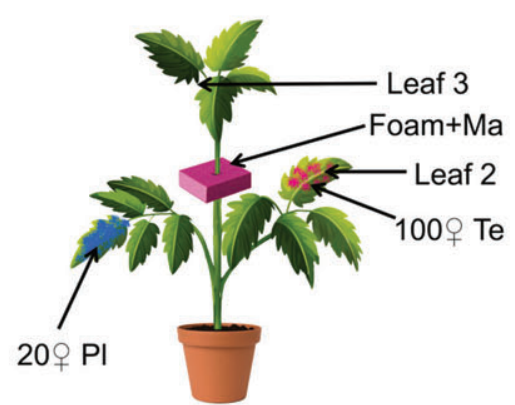

Fungus-treated foam T7(Te + PI)

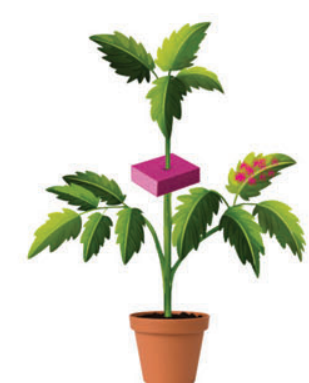

Untreated foam T6 (Te - PI)

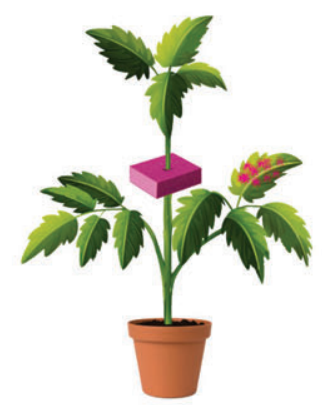

Fungus-treated foam T8 (Te - PI)

Figure 2. Experiment 1: experimental devices for testing the efficacy of a fungus-treated foam disc placed below or above the disc to control T. evansi (Te). Experiment 2: experimental devices for testing the efficacy of a fungus-treated foam disc placed below or above infested leaves to control T. evansi. The second experiment combined the fungus-treated foam disc with the release of $P$. longipes (PI). Ma, Metarhizium anisopliae. 
$(T e+P I) ; T 6$, untreated foam with $T$. evansi but without $P$. longipes $(T e-P l) ; T 7$, fungus-treated foam with $T$. evansi and $P$. longipes $(T e+P l)$; and $T 8$, fungus-treated foam with $T$. evansi but without $P$. longipes $(T e-P l)$. Twenty female predatory mites were starved for $24 \mathrm{~h}$ and released on leaflet L1, 3 days after the infestation of tomato plants with $100 \mathrm{~T}$. evansi females. Treatments were randomised and repeated four times.

\subsubsection{Assessment of the efficacy of treatments}

For 15 days after treatment application, the percentage of leaflet infestation by T. evansi was determined every 3 days by recording the number of red spider mites alive per leaflet per plant. In the experiment on the interaction between the fungus-treated foam and predatory mites, the number of mobile stages of spider mites and predatory mites was counted on the foam and above the foam at days 6 and 15 post-treatment. The leaf mean damage index (LMDI) or damage index (ID) was determined using a scale from 0 (no damage) to 5 (the leaf beginning to shrivel), following a previously described method. ${ }^{23}$ To determine the persistence of conidia on the foam, the fungus-treated foam was reused in successive trials without re-impregnation. The foam was removed at 15 days post-treatment and placed on 45-day-old non-infested plants. Leaf L2 was then infested with 100 T. evansi females as described above. The protocol was repeated for the third time after 15 days. In the control treatment, foam was not impregnated with the fungus. In the three successive assays, leaf infestation was determined every 3 days for 15 days post-treatment following the application of treatments as described above.

\subsection{Data analysis}

A non-parametric test, the Kruskal-Wallis test, was used to analyse the effects of the treatments on mite infestation and leaf damage. The response variable was the average infestation or LMDI per plant. The first time-point (day 0) was excluded from the calculation of these values because it was too early for treatments to have had an effect. Post hoc pairwise tests were performed with the Wilcoxon method. All the analyses were carried out using the statistical software JMP $12 .{ }^{24}$

\section{RESULTS}

\subsection{Tomato leaf infestation}

The mean percentage of leaflet infestation by mites increased from $9 \pm 0.3 \%$ at day 0 to $100 \pm 0.1 \%$ (mean \pm Standard error) at day 15 post-treatment in the control ( $\mathrm{T} 1$ and $\mathrm{T} 2$ ) and in the treatment with fungus-treated foam placed below the mite-infested leaflet (T4) (Fig. 3). Leaves in these treatments were completely damaged by mites and died off. At the same time, leaf infestation was significantly lower ( $\left.\chi^{2}=13.06 ; \mathrm{df}=3 ; P=0.0045\right)$ when fungus-treated foam was placed above the mite-infested leaf (T3) (Fig. 3).

\subsection{Leaf mean damage index}

Regardless of the location of the foam in treatments T1 (untreated control with $T$. evansi infestation on leaf L2 below the foam), T2 (untreated control with T. evansi infestation on leaf L3 above the foam) and T4 (fungus-treated foam with T. evansi infestation on leaf L3 above the foam), the ID was $\geq 1$. Leaves in these treatments were completely damaged by mite infestation. However, in treatment T3 (fungus-treated foam with T. evansi infestation on leaf L2 below the foam), the ID of leaves located above the fungus-treated foam was practically nil and the ID of leaves below the fungus-treated

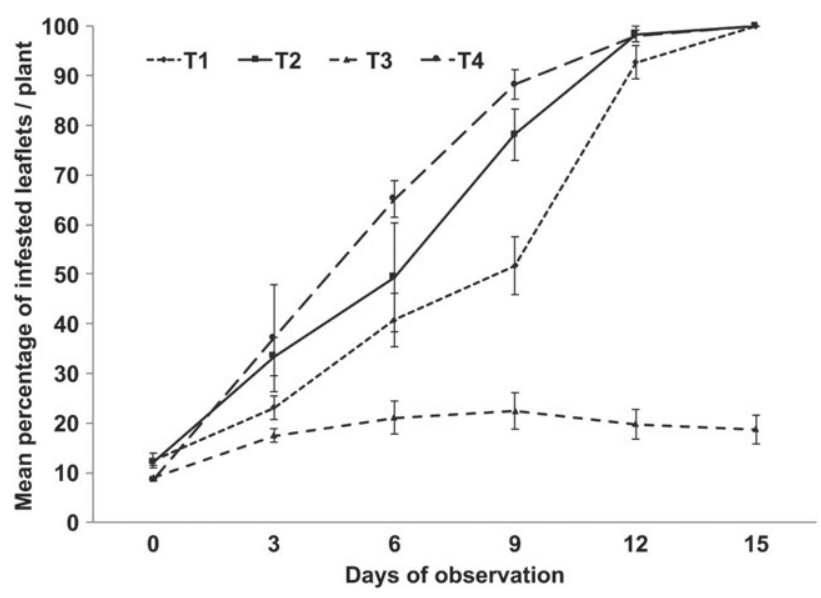

Figure 3. Mean percentage of tomato leaflets infested by $T$. evansi per plant and per observation date. The following treatments were applied:T1, untreated control with T. evansi infestation on leaf $\mathrm{L} 2$ below the foam; $\mathrm{T} 2$, untreated control with $T$. evansi infestation on leaf $L 3$ above the foam; $T 3$, fungus-treated foam with $T$. evansi infestation on leaf $L 2$ below the foam; and T4, fungus-treated foam with T. evansi infestation on leaf $\mathrm{L} 3$ above the foam. On the first day (T0), 100 females of T. evansi were deposited on leaf $L 2$ just below the foam or on leaf $L 3$ just above the foam. The treatments were replicated four times and bars indicate the standard errors.

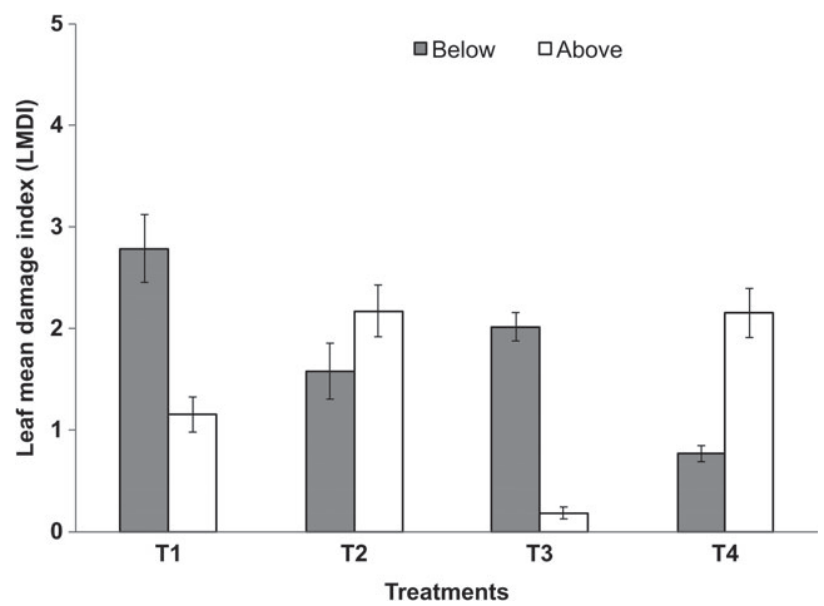

Figure 4. Tomato leaf mean damage index (LMDI) for damage by T. evansi recorded on the leaves below and above the fungus-treated foam. The following treatments were applied: $\mathrm{T} 1$, untreated control with $T$. evansi infestation on leaf $L 2$ below the foam; $T 2$, untreated control with $T$. evansi infestation on leaf L3 above the foam; T3, fungus-treated foam with $T$. evansi infestation on leaf $\mathrm{L} 2$ below the foam; and $\mathrm{T} 4$, fungus-treated foam with $T$. evansi infestation on leaf $L 3$ above the foam. The treatments were replicated four times and bars indicate the standard errors.

foam was 2. The Kruskal-Wallis test showed a significant difference $\left(\chi^{2}=5.46 ; \mathrm{df}=1 ; P=0.02\right)$ between the treatments (Fig. 4). These results showed that the infestation level was linked to the position of the fungus-treated foam; the results are congruent with the results on infestation intensity (Fig. 3).

\subsection{Persistence of fungus-treated foam}

The persistence of fungus-treated foam was evaluated in terms of percentage infestation of tomato leaflets by $T$. evansi. In the control treatments, the infestation of tomato leaflets by mites increased considerably from the initial deposit to reach $100 \pm 0 \%$ at day 15 post-treatment in all the three experimental sets 


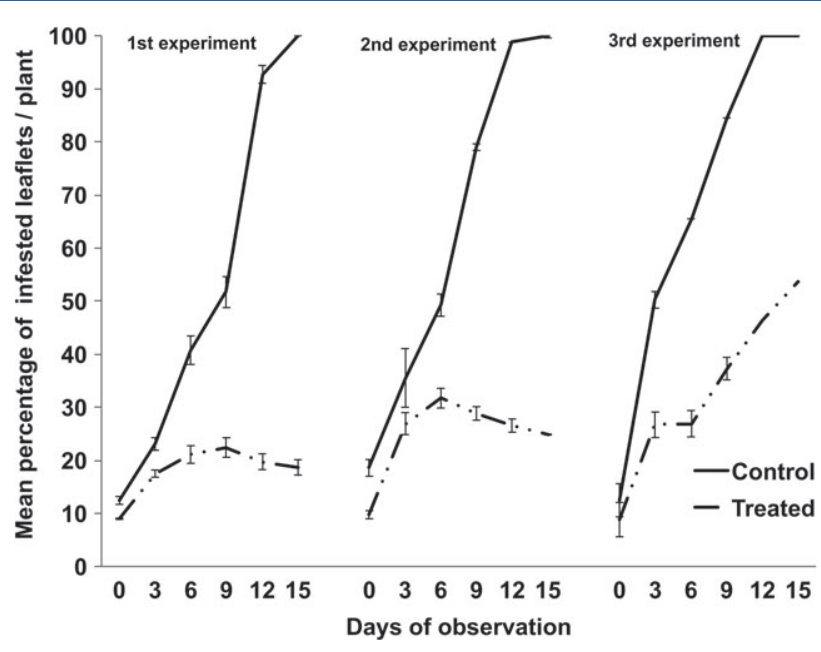

Figure 5. Mean percentage of tomato leaflets infested by T. evansi per plant and per observation date. The following treatments were applied:T1, untreated control with $T$. evansi infestation on leaf $L 2$ below the foam; $T 3$, fungus-treated foam with $T$. evansi infestation on leaf $L 2$ below the foam. The fungus-treated foam was reused in two subsequent experiments. On the first day of each experiment (T0), 100 females of T. evansi were deposited on leaf $L 2$ just below the foam. The arrows indicate the dates of mite infestation. The treatments were replicated four times and bars indicate the standard errors.

(Fig. 5). In the fungus treatments, the percentage of mite-infested leaflets was significantly lower $\left(\chi^{2}=5.33\right.$; $\left.\mathrm{df}=1 ; P=0.02\right)$. For example, when the foam was used for the first time (first 15 days post-treatment), $19 \pm 1.44 \%$ leaflet infestation was recorded. When the same fungus-treated foam was used for the second time (i.e. 30 days post-treatment), leaflet infestation was $25 \pm 1.24 \%$ while it increased to $54 \pm 2.12 \%$ following the third use (i.e. 45 days post-treatment) (Fig. 5). The leaflet under the fungus-treated foam was highly infested while there were no mites on the leaflet above the foam. Overall, fungus-treated foam could still protect tomato plants for at least 45 days post-treatment under our experimental conditions.

\subsection{Interaction between fungus-treated foam and predatory mites on $T$. evansi infestation}

The percentage infestation by mites on tomato leaflets increased from $14 \pm 0.8 \%$ to $100 \pm 0 \%$ at day 15 post-treatment in T6 (untreated foam; $\mathrm{Te}-\mathrm{Pl}$ ) while it increased from $13 \pm 0.7 \%$ to $47 \pm 2.7 \%$ after 15 days in treatment T5 where predatory mites were released (untreated foam; $T e+P l$ ) (Fig.6). In T8 (fungus-treated foam; $T e-P l$ ), the percentage of tomato leaflet infestation by mites was $20 \pm 3.5 \%$ after 15 days of observation while it was $18 \pm 1.03 \%$ in the treatment T7 (fungus-treated foam; $T e+P l)$ (Fig. 6). The differences were significant $\left(\chi^{2}=13.5000\right.$; $\mathrm{df}=3 ; \quad P=0.0037$ ) between T5 (untreated foam; Te $+P I)$, T6 (untreated foam; $\mathrm{Te}-\mathrm{Pl}$ ), T7 (fungus-treated foam; $\mathrm{Te}+\mathrm{Pl}$ ) and T8 (fungus-treated foam; $T e-P I$ ). However, the non-parametric comparisons for each pair using the Wilcoxon method did not show any statistically significant difference between the two treatments T7 and T8 $(P=0.11)$.

Regardless of the treatment, the LMDI was $\geq 1$ below the foam (Fig. 7) while it was nil above the foam in treatment T5 (untreated foam; $T e+P I$ ), T7 (fungus-treated foam; $T e+P l$ ) and T8 (fungus-treated foam; $T e-P I$ ), which is consistent with the results on mite infestation (Fig.6). There was a significant difference between treatments T5, T7, T8 and T6 $\left(\chi^{2}=3.94 ; \mathrm{df}=1 ; P=0.04\right)$.

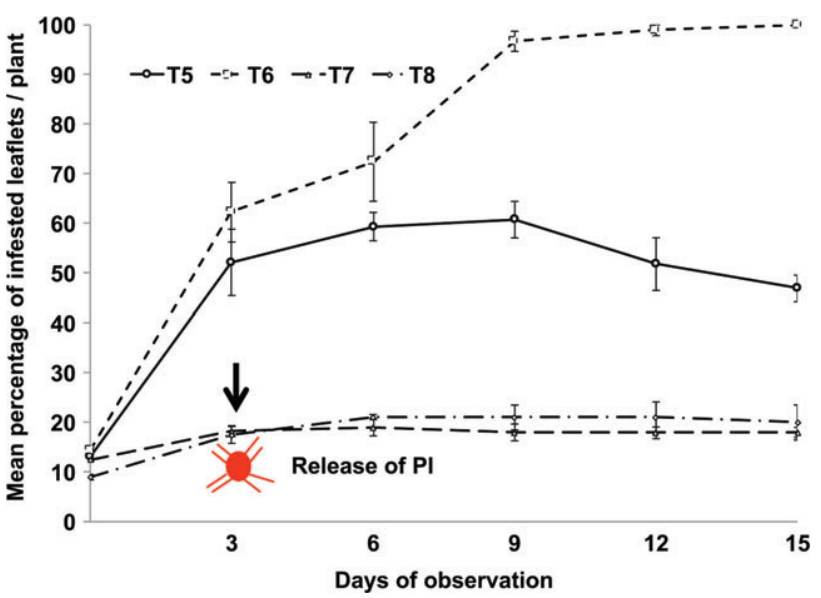

Figure 6. Mean percentage of tomato leaflets infested by T. evansi per plant and per observation date. The following treatments were applied:T5, untreated foam with $T$. evansi and $P$. longipes $(T e+P l) ; T 6$, untreated foam with $T$. evansi but without $P$. longipes $(T e-P I) ; T 7$, fungus-treated foam with T. evansi and $P$. longipes $(T e+P l) ; T 8$, fungus-treated foam with $T$. evansi but without $P$. longipes $(T e-P I)$. On the first day (T0), 100 females of $T$. evansi were deposited on leaf $L 2$ just below the foam or on leaf $L 3$ just above the foam. On day $T 0+3,20$ females of $P$. longipes were released on leaf $L 1$. The treatments were replicated four times and bars indicate the standard errors. The solid arrow indicates the date of mite infestation. The dashed arrow indicates the date of predatory mite release.

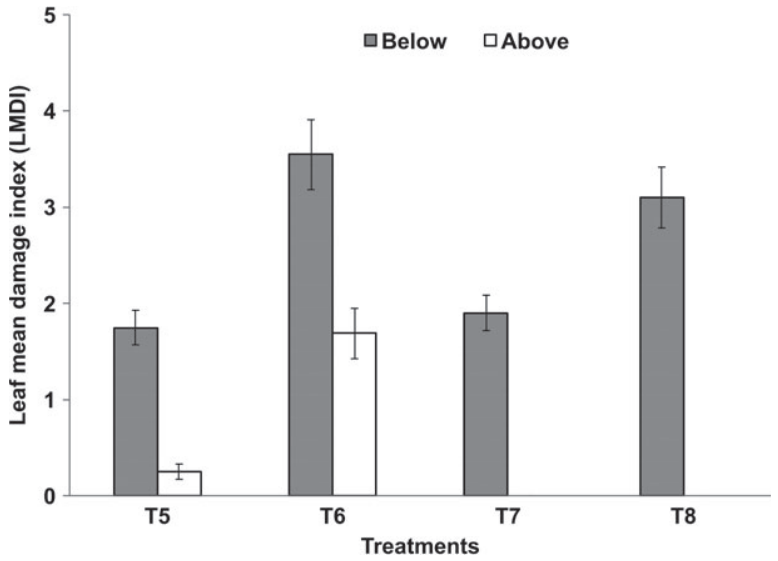

Figure 7. Leaf mean damage index (LMDI) for damage by T. evansi on tomato plants recorded for the leaves below and above the foam. The following treatments were applied: T5, untreated foam with T. evansi and $P$. longipes $(T e+P I) ; T 6$, untreated foam with $T$. evansi but without $P$. longipes $(T e-P l)$; T7, fungus-treated foam with $T$. evansi and $P$. longipes $(T e+P l)$, and T8, fungus-treated foam with $T$. evansi but without $P$. longipes $(T e-P l)$. The treatments were replicated four times and bars indicate the standard errors.

The predatory mite and the fungus-treated foam seemed to have the same effect on mite infestation.

The mean number of T. evansi recorded on leaf 3 was significantly higher in treatment T6 (untreated foam; Te - PI) (465 T. evansi) than in treatment T5 (untreated foam; $T e+P I)$ (235 T. evansi), while it was almost the same in treatments T7 (fungus-treated foam; $T e+P l$ ) and T8 (fungus-treated foam; $T e-P I)(0$ and $1 \mathrm{~T}$. evansi, respectively) (Table 1). These results confirmed the previous observations for LMDI (Fig. 7).

The mean number of $P$. longipes recorded on the foam was not significantly different in T5 and T7 (86 and 81 P. longipes, respectively). The fungus-treated foam seemed not to affect the predatory mites. 
Table 1. Mean number of T. evansi and $P$. longipes on the foam and on leaf 3 (L3), 15 days post-treatment. The following treatments were applied: T5, untreated foam with $T$. evansi and $P$. longipes $(T e+P l)$; T6, untreated foam with $T$. evansi but without $P$. longipes $(T e-P I) ; T 7$, fungus-treated foam with $T$. evansi and $P$. longipes $(T e+P l)$, and T8, fungus-treated foam with $T$. evansi but without $P$. longipes $(T e-P l)$

\begin{tabular}{|lcc|} 
Treatment & $\begin{array}{c}\text { T. evansi } \\
\text { on leaf } 3\end{array}$ & $\begin{array}{c}\text { P. longipes } \\
\text { on foam }\end{array}$ \\
\hline T5, untreated foam; $T e+P I$ & $235 \pm 1 \mathrm{~b}$ & $86 \pm 4$ \\
T6, untreated foam; $T e-P I$ & $465 \pm 50 \mathrm{a}$ & - \\
T7, fungus-treated foam; $T e+P I$ & $0 \pm 0 \mathrm{c}$ & $81 \pm 2$ \\
T8, fungus-treated foam; $T e-P I$ & $1 \pm 1 \mathrm{c}$ & - \\
$F$ & 86.56 & - \\
$P$-value & $<0.0001$ & 0.57 \\
\hline a, b, c Post hoc pairwise tests with the Wilcoxon method. \\
\hline
\end{tabular}

\section{DISCUSSION}

The present study showed that tomato plants could be protected against $T$. evansi when fungus-treated foam was placed above mite-infested leaves. Moreover, protection could last for 30-45 days post-treatment, resulting in a significant reduction in the infestation rate. These results can be explained by the mite behaviour of moving along the plant stem in a circadian fashion. ${ }^{20,25,26}$ Subsequently, mites would be contaminated by the fungus and unable to colonise new leaves, except those under the fungus-treated foam.

One of the main challenges of using entomopathogenic fungi in the field is their short persistence in the environment as a result of their vulnerability to UV radiation. In the present study, the fungus-treated foam could protect the tomato plant for up to 30 days post-treatment in laboratory conditions with only $25 \pm 1.2 \%$ leaflet infestation $(54 \pm 2.1 \%$ leaflet infestation 45 days post-treatment) (Fig. 5). These results suggest that the fungus-treated foam approach could be a sustainable strategy against this pest and an alternative to expensive inundative applications, as suggested by Mfuti et al. ${ }^{27}$

The fungus-treated foam and the release of $P$. longipes did not provide additional benefits to the fungus alone in terms of mite infestation, the LMDI and the number of $T$. evansi recorded on leaf 3. The treated foam used alone or combined with the predatory mites had the same effect on mite infestation in treatments T5 and T7. The effectiveness of $P$. longipes in controlling T. evansi populations has been reported elsewhere under laboratory conditions. ${ }^{17,19,21}$ Therefore, there might not be benefits in combining $M$. anisopliae-treated foam and P. longipes for T. evansi control on a tomato crop. Similar results were reported by Maniania et al., ${ }^{13}$ who did not find any additional effect of combining $M$. anisopliae and $P$. longipes in the control of T. evansi populations in the screenhouse and under field conditions. No dead predatory mites were observed on the foam and their numbers were similar in treatments T5 (untreated foam) ( 86 predatory mites) and T7 (fungus-treated foam) (81 predatory mites). These results confirm observations by Maniania, who reported compatibility between $P$. longipes and $M$. anisopliae, as exposure of $P$. longipes to a conidial suspension of $M$. anisopliae did not cause mortality of predatory mites in the laboratory (Maniania, unpubl. data).

The new approach proposed here could reduce the number of inocula applied and improve fungal persistence. As linalool or methyl salicylate are known to attract predatory mites in the field ${ }^{28}$ it might be possible to combine fungus-treated foam with these compounds. However, their compatibility must first be tested. Furthermore, open field experiments are needed to confirm the effectiveness of the fungus-treated foam applied alone or in combination with the release of $P$. longipes in controlling spider mites on roses and tomatoes in greenhouses. We also suggest carrying out the compatibility test of $M$. anisopliae with $P$. longipes in the laboratory at high humidity to simulate greenhouse conditions.

\section{ACKNOWLEDGEMENTS}

This study was made possible by the generous support of the American people through the US Agency for International Development (USAID) under Award No. EPP-A-00-09-00004, with additional support from Michigan State University and the CIRAD - Agricultural Research for Development. The study also received financial support from CIRAD and the International Centre of Insect Physiology and Ecology (ICIPE).

We thank Brian Mwashi from ICIPE and Koffi Negloh from International Institute of Tropical Agriculture (IITA) for their technical assistance.

\section{AUTHOR CONTRIBUTIONS}

Thibaud Martin and Komi K. Fiaboe made substantial contributions to the idea of using Metarhyzium anisopliae fixed on the foam.

Ginette Y. Azandémè Hounmalon carried out the experimentation, the acquisition of data, and analysis and interpretation of data, and wrote the manuscript.

Nguya K. Maniania assisted in the use of entomopathogenic fungi, and was involved in drafting the manuscript and reviewing it critically for important intellectual content.

Niassy Saliou and Simon Fellous carried out the statistical analysis and made comments on the manuscript.

Serge Kreiter and Emilie Delétré also made comments on the manuscript for its improvement.

All authors have agreed on the order in which their names appear in the manuscript.

\section{REFERENCES}

1 Gerson U, Smiley RL and Ochoa R, Mites (Acari) for Pest Control. Blackwell, Oxford (2003).

2 Kennedy GG, Tomato pests, parasitoids and predators: tritrophic interactions involving the genus Lycopersicon. Ann Rev Entomol 48:51-72 (2003)

3 Knapp M, Wagener B and Navajas M, Molecular discrimination between the spider mite Tetranychus evansi Baker \& Prichard, an important pest of tomatoes in southern Africa, and the closely related species T. urticae Koch (Acarina: Tetranychidae). Afr Entomol 11:300-304 (2003).

4 Leite GLD, Picanco M, Zanuncio JC and Marquini F, Factors affecting mite herbivory on eggplants in Brazil. Exp App Acarol 31:243-252 (2003).

5 Migeon A, Ferragut F, Escudero-Colomar LA, Fiaboe K, Knapp M, de Moraes GJ et al., Modelling the potential distribution of the invasive tomato red spider mite, Tetranychus evansi (Acari: Tetranychidae). Exp Appl Acarol 48:199-212 (2009).

6 Sibanda T, Dobson HM, Cooper JF, Manyangarirwa W and Chiimba W, Pest management challenges for smallholder vegetable farmers in Zimbabwe. Crop Prot 19:807-815 (2000).

7 Azandémè Hounmalon GY, Affognon HD, Komlan FA, Tamò M, Fiaboe KKM, Kreiter $S$ et al., Farmers' control practices against the invasive red spider mite, Tetranychus evansi Baker \& Pritchard in Benin. Crop Prot 76:53-58 (2015). 
8 Saunyama IGM and Knapp M, The effects of pruning and trellising of tomatoes (Lycopersicon esculentum Mill.) on red spider mite (Tetranychus evansi Baker \& Pritchard) incidence and crop yield in Zimbabwe. Afr Crop Sci J 11:269-277 (2003).

9 Boubou A, Migeon A, Roderick GK and Navajas M, Recent emergence and Worldwide spread of the red tomato spider mite, Tetranychus evansi: genetic variation and multiple cryptic invasions. Biol Inv 13:81-92 (2011).

10 Smith Meyer MKP, Mite Pests and their Predators on Cultivated Plants in Southern Africa Vegetables and Berries. Plant Protection Research Institute, Handbook no. 6. ARC-Plant Protection Research Institute, Pretoria, p. 90 (1996).

11 van Leeuwen $T$, Vanholme $B$, van Pottelberge $S$, van Nieuwenhuyse $P$, Nauen R, Tirry L et al., Mitchonfrial heteroplasmy and the evolution of insecticide resistance: non-mendelian inheritance in action. Proc Nat Acad Sci 105:5980-5985 (2008).

12 Nyoni BN, Gorman K, Mzilahowa T, Williamson MS, Navajas M, Field LM et al., Pyrethroid resistance in the tomato red spider mite, Tetranychus evansi, is associated with mutation of the para-type sodium channel. Pest Manage Sci 67:891-897 (2011).

13 Maniania NK, Ekesi S, Kungu MM, Salifu D and Srinivasan R, The effect of combined application of the entomopathogenic fungus Metarhizium anisopliae and the release of predatory mite Phytoseiulus longipes for the control of the spider mite Tetranychus evansi on tomato. Crop Prot 90:49-53 (2016).

14 Wekesa VW, Maniania NK, Knapp M and Boga HI, Pathogenicity of Beauveria bassiana and Metarhizium anisopliae to the tobacco spider mite Tetranychus evansi. Exp Appl Acarol 36:41-50 (2005).

15 Bugeme DM, Knapp M, Ekesi S, Chabi-Olaye A, Boga HI and Maniania NK, Efficacy of Metarhizium anisopliae in controlling the two-spotted spider mite Tetranychus urticae on common bean in screenhouse and field experiments. Ins Sci 22:121-128 (2014).

16 Maniania NK, Bugeme DM, Wekesa VW, Delalibera I Jr and Knapp M, Role of entomopathogenic fungi in the control of Tetranychus evansi and Tetranychus urticae (Acari: Tetranychidae), pests of horticultural crops. Exp Appl Acarol 46:259-274 (2008).

17 Furtado IP, de Moraes GJ, Kreiter S, Tixier MS and Knapp M, Potential of a Brazilian population of the predatory mite Phytoseiulus longipes as a biological control agent of Tetranychus evansi (Acari: Phytoseiidae, Tetranychidae). Biol Control 42:139-147 (2007).

18 Silva FR, Moraes GJ, Gondim MGC, Knapp M, Rouam SL, Paes JLA et al., Efficiency of Phytoseiulus longipes Evans as a control agent of
Tetranychus evansi Baker \& Pritchard (Acari: Phytoseiidae: Tetranychidae) on screenhouse tomatoes. Neotrop Entomol 39:991-995 (2010).

19 Ferrero M, Calvo FJ, Atuahiva T, Tixier MS and Kreiter S, Biological control of Tetranychus evansi Baker \& Pritchard and Tetranychus urticae Koch by Phytoseiulus longipes Evans in tomato greenhouses in Spain [Acari: Tetranychidae, Phytoseiidae]. Biol Control 58:30-35 (2011).

20 Azandémè Hounmalon GY, Fellous S, Kreiter S, Fiaboe KKM, Subramanian S, Kungu M et al., Dispersal behavior of Tetranychus evansi and T. urticae on tomato at several spatial scales and densities: implications for integrated pest management. PLoS One 9:e95071 (2014).

21 Ferrero M, de Moraes GJ, Kreiter S, Tixier MS and Knapp M, Life tables of the predatory mite Phytoseiulus longipes feeding on Tetranychus evansi at four temperatures (Acari: Phytoseiidae, Tetranychidae). Exp Appl Acarol 41:45-53 (2007).

22 Bugeme DM, Maniania NK, Knapp M and Boga HI, Effect of temperature on virulence of Beauveria bassiana and Metarhizium anisopliae isolates to Tetranychus evansi. Exp Appl Acarol 46:275-285 (2008).

23 Hussey NW and Scopes NEA, Greenhouse vegetables (Britain), Spider Mites, Their Biology, Natural Enemies and Control, Vol. 1B. ed. by Helle W and Sabelis MW. Elsevier, Amsterdam. pp. 285-297 (1985).

24 JMP 12.2 Annual License Updaters. Statistical Discovery from SAS software - Release 12 - DEC 2015.

25 Pralavorio $M$, Fournier $D$ and Millot $P$, Activité migratoire des tétranyques: mise en évidence d'un rythme. Entomoph 34:129-134 (1989).

26 Clotuche G, Mailleux A-C, Astudillo Fernandez A, Deneubourg J-L, Detrain $C$ and Hance T, The formation of collective silk balls in the spider mite Tetranychus urticae Koch. PLoS One 6:e18854 (2011).

27 Mfuti DK, Subramanian S, van Tol RW, Wiegers GL, de Kogel WJ, Niassy $S$ et al., Spatial separation of semiochemical Lurem-TR and entomopathogenic fungi to enhance their compatibility and infectivity in an autoinoculation system for thrips management. Pest Manage Sci 72:131-139 (2016).

28 Azandémè Hounmalon GY, Baldwyn Torto, Fiaboe KKM, Subramanian Sevgan, Serge Kreiter and Thibaud Martin, Visual, vibratory, and olfactory cues affect interactions between the red spider mite Tetranychus evansi and its predator Phytoseiulus longipes J Pest Sci 89:137-152 (2016). 


\section{Research Article}

The present study investigated the efficacy of fungus-treated foam placed above or below the third Tetranychus evansi-infested tomato leaf.

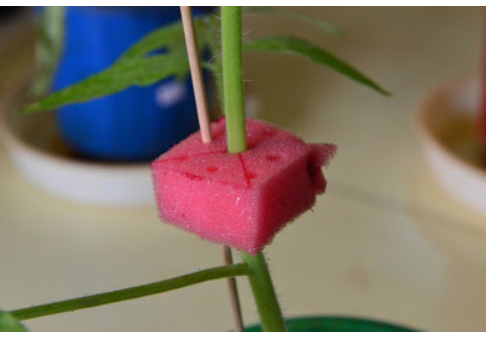

Performance of Metarhizium anisopliae-treated foam in combination with Phytoseiulus longipes Evans against Tetranychus evansi Baker $\&$ Pritchard (Acari: Tetranychidae) $\dagger$

Ginette Y Azandémè Hounmalon, Nguya K Maniania, Saliou Niassy, Simon Fellous, Serge Kreiter, Emilie Delétré, (ID Komi KM Fiaboe and Thibaud Martin 